\title{
Avian tuberculosis in a Lady Amherst's pheasant Chrysolophus amherstiae
}

\author{
Pedro P. Álvarez ${ }^{\mathrm{a}, \mathrm{b}}$, Manuel Moronia ${ }^{\mathrm{a}}$, Claudio Verdugo ${ }^{\mathrm{a}, \mathrm{b}^{*}}$
}

\begin{abstract}
We report a case of a Lady Amherst's pheasant (Chrysolophus amherstiae) with diffuse granulomatous lesions in liver, spleen and intestine. Using histopathological and molecular diagnosis we detected Mycobacterium avium subsp. avium, etiological agent of avian tuberculosis. Further studies are needed to understand the role of wild birds in the persistence and transmission of this pathogen.

Key words: pheasant, Mycobacterium avium, PCR, avian tuberculosis.
\end{abstract}

RESUMEN. Reportamos un caso de un faisán Lady Amherst (Chrysolophus amherstiae) con lesiones granulomatosas difusas en hígado, bazo e intestino. Usando diagnóstico histopatológico y molecular detectamos Mycobacterium avium subsp. avium, agente etiológico de tuberculosis aviar. Se requieren más estudios para entender el rol de aves silvestres en la persistencia y transmisión del patógeno.

Palabras clave: faisán, Mycobacterium avium, PCR, tuberculosis aviar.

Avian tuberculosis (AvTB) is a contagious disease affecting a wide range of domestic and wild bird species. AvTB is caused by Mycobacterium avium subsp. avium (MAA), and less frequently by Mycobacterium genavense and Mycobacterium bovis. MAA is a saprophytic and aerobic Gram positive bacillum with a slow glycerol-dependent growth (Converse et al 2007). Individuals become infected by consuming contaminated food, water or soil. Affected animals may show opaque feathers, inappetence, diarrhea, loss of muscle mass, and death (Muttalib and Riddell 1988, Converse 2007). Multiple hepatic and splenic granulomas with a yellowish to whitish caseonecrotic center are considered characteristic of the disease, which may also be present in small intestine, bone marrow, lungs, mesentery, heart, ovaries and subcutaneous (Muttalib and Riddell 1988, Converse 2007).

In South America, AvTB has been previously described in Uruguay, Brazil, Argentina, and Colombia affecting wild, farmed, and pet-zoo birds. In wild South American birds, AvTB has been confirmed in black-chested buzzard-eagle (Geranoaetus melanoleucus), bufflehead (Bucephala albeola), northern shoveler (Anas clypeata), common raven (Corvus corax), and dusky-legged guan (Penelope obscura) (Castro-Ramos et al 2014). In farmed birds has been described in rheas (Rhea americana), chickens (Gallus sp.) (Jorge et al 2007), common pheasant (Phasianus colchicus) and Indian peafowl (Pavo cristatus) (Castro-Ramos et al 2014). In pets or zoo birds, AvTB has been confirmed in budgerigar (Melopsittacus undulatus), blue-fronted amazon (Amazona aestiva), double-striped thick-knee

\footnotetext{
Accepted: 19.06.2017.

anstituto de Patología Animal, Facultad de Ciencias Veterinarias, Universidad Austral de Chile, Valdivia, Chile.

bPrograma de Investigación Aplicada en Fauna Silvestre, Facultad de Ciencias Veterinarias, Universidad Austral de Chile, Valdivia, Chile.

*Corresponding author: C Verdugo; Los Laureles s/n, Edificio Federico Saelzer, 3er piso, Valdivia, Chile; claudioverdugo@uach.cl
}

(Burhinus bistriatus), little-chachalaca (Ortalis motmot), burrowing owl (Athene cunicularia), sickle-winged guan (Chamaepetes goudotii) and yellow-crowned parrot (Amazona ochrocephala) (Neira et al 2006, Godoy et al 2009). In Chile, although AvTB has been officially reported affecting poultry ${ }^{1}$ there are no further information of clinical cases, pathology, and diagnoses. Here, we report a severe case of AvTB in a Lady Amherst's pheasant (Chrysolophus amherstiae) from a private flock, based on postmortem, histopathological and molecular findings.

An adult female of Chrysolophus amherstiae was found dead in her nesting box on August 2015. The animal belonged to a mixed breeding farm of exotic birds, including pheasants and quails (200 animals aprox.), located in Valdivia, Chile. The flock was reported to have had mortalities during the last four weeks with no further clinical signs other than loss of appetite and reluctance to move.

Post mortem examination revealed an enlarged liver with numerous yellowish coalescent granulomas from $0.1-2 \mathrm{~cm}$ diameter affecting surface and organ parenchyma (figure 1A). The spleen parenchyma was almost totally effaced by similar granulomatous lesions. The jejunum, ileum, ileocaecal junction and colon also showed multiple transmural granulomatous nodules ranging from $0.5-6 \mathrm{~cm}$ diameter. Affected tissues were fixed in $10 \%$ formalin and in $90 \%$ ethanol for further histopathological and molecular diagnoses, respectively. Histopathological findings from selected tissues revealed multifocal to coalescing inflammatory granulomas with necrotic center surrounded by multiple epitheloid macrophages, lymphocytes, and few heterophils followed by Langhans-type multinucleated giant cells (figure 1B and 1C). Fibrous connective tissue surrounded granulomas in the liver and spleen. From one to seven acid-fast bacilli were observed in the cytoplasm of

http://www.sag.cl/ambitos-de-accion/situacion-sanitaria-nacional (Accessed 10 de June 2016) 


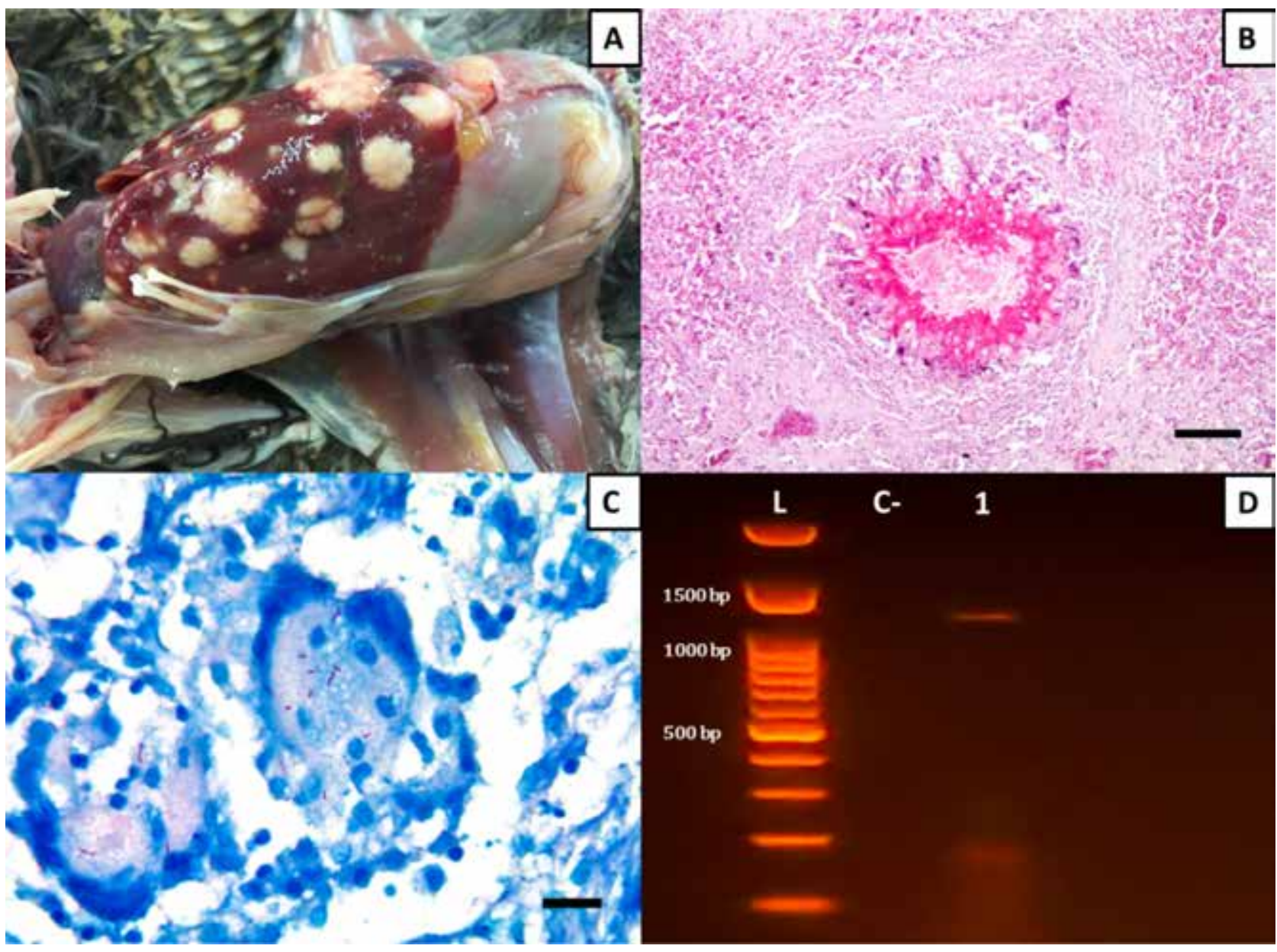

Figure 1. Macroscopic, histological and molecular findings from a Lady Amherst's pheasant Chrysolophus amherstiae infected with M. avium subsp. avium. A. Presence of multiple granulomas of different sizes affecting hepatic parenchyma. B. Photomicrograph of a granuloma with a central of necrosis and surrounded by epitheloid macrophages, lymphocytes, and heterophils. A group of Langhanstype multinucleated giant cells is evident in the top right of the picture next to a peripheral fibrosis (H\&E stain, 10X, Bar=100 $\mu \mathrm{m})$. C. Presence of acid-fast bacilli in the cytoplasm of multinucleated giant cells (ZN stain, 100X, Bar=10 $\mu \mathrm{m})$. D. Detection of Mycobacterium avium subsp. avium from liver sample of the pheasant using PCR (Svastova et al 2002). Lane L: AccuRuler 100 bp Plus DNA RTU Ladder. Lane C-: negative control. Lane 1: liver tissue from pheasant.

multinucleated giant cells surrounding the granulomas in samples stained with Ziehl-Neelsen (figure 1C). For further identification, DNA was extracted from a hepatic granuloma using a commercial $\mathrm{kit}^{2}$. A $180 \mathrm{bp}$ fragment of $16 \mathrm{~S}$ rRNA gene was first amplified using a multiplex PCR protocol with MYCGEN-F, MYCGEN-R and MYCAV-R primers for $M$. avium complex diagnoses, as previously described (Wilton and Cousins 1992). Amplicon of the expected size was purified and sequenced. Edited sequence (accession number SUB 1955274) revealed a 99\% sequence identity with other partial 16S rRNA sequences of M. avium complex available in database using BLAST (http://blast.ncbi.nlm. nih.gov/Blast.cgi). To determine the MAA, another PCR targeting a different fragment of the16S rRNA gene was

DNeasy Blood \& Tissue Kit, Qiagen, Valencia, California, USA amplified using P1-IS901 and P2-IS901 primers (Svastova et al 2002). The molecular typing revealed a band pattern consistent to MAA (figure 1D).

Infections caused by subspecies of $M$. avium complex have been widely recognized for causing diseases and severe economic losses in animal and human population worldwide. Here, we were able to confirm a case of AvTB due to MAA in a Lady Amherst's pheasant through macroscopic, histopathologic, and molecular diagnostic techniques. The main lesions caused by MAA are caseonecrotic granulomas in liver and spleen, but also intestines, kidneys, bone marrow, air sacs, lungs and skin (Kul et al 2005, Kelly et al 2013). In this case, granulomas were evident in liver, spleen and intestine, but not at respiratory organs, suggesting that the infection was through oral route. Similar lesions have been previously described in pheasants affected by MAA (Kul et al 2005), and other birds (Gerhold and 
Fischer 2005). The large number of acid-fast bacilli in the cytoplasm of multinucleated giant cells stained with $\mathrm{ZN}$ is also characteristic of MAA infection which is slightly higher than acid-fast bacilli found in M. bovis infection, a less common agent of AvTB (Sánchez et al 2016). Thus, for fully identification of the agent, a molecular typing is necessary, which in this case was performed by using a multiplex PCR and sequencing for detection MAA.

Pheasants are a common farm bird, and are highly susceptible to MAA infection (Kul et al 2005). In farmed and zoo birds, the transmission of the Mycobacteria can be facilitated by the presence of wild birds in the enclosure (Tell et al 2001) or the presence of undetected infected birds in the flock. Persistently infected wild or feral birds, such as sparrows and pigeons, may easily enter the enclosures and either be in contact with the susceptible flock or contaminate the food and/or the water with the bacteria. Hejlicek and Treml (1993) detected the presence of Mycobacterium avium in sparrows in close association with poultry. Sparrows are considered not only a source, but also an indicator of environmental Mycobacterium avium loads (Hejlicek and Treml 1993) In this case, house sparrows (Passer domesticus) were present in the enclosure and may have an important role in the persistence and transmission of the bacteria among birds. Intrinsic factors of the captivity such us overcrowding, poor sanitation, inadequate ventilation, and excessive humidity may increase the risk of AvTB transmission (Gerhold and Fischer 2005). Hence, transmission must be controlled by reducing the contact with other birds (i.e. perimeter fence), performing strict quarantine for new birds, and the sacrifice of infected individuals. Since MAA may persist in the environment from several months to years, disinfection in cages and pens and annual removal of the soil and drainage of wells is also recommended (Converse 2007).

In Chile, there are no further reports on cases of avian tuberculosis in birds and domestic animals other than some reports of the Chilean Livestock and Agriculture Department affecting poultry. The overall incidence of human tuberculosis in Chile is relatively low (i.e. 13 cases per 100,000 population) $)^{3}$. The transmission of AvTB to humans, although not frequent, has been previously documented (Dhama et al 2011). The surveillance and the diagnostic capacity are deficient and additional efforts are required. Therefore, the reporting of AvTB need to be improved, integrating approaches that encompass human, wildlife and domestic animal health.

Due to the long latency periods, the difficulties in bacteriological diagnosis in wildlife and poultry birds, the lack of effective treatments and the persistence in the

http://web.minsal.cl/sites/default/files/Informe_tbc_2014.pdf (Accessed 26 Sep 2016) environment, MAA still poses a serious threat to both captive and wild populations. In Chile, the reports of AvTB in birds are scarce and it is probably an underreported disease. Therefore, further investigations are necessary to determine the prevalence and understand the persistence mechanisms at local and regional scale of MAA in both wild and domestic birds in Chile, and future cases of avian tuberculosis should be addressed using an integrated focus, by histopathologic and molecular analysis, and detection of possible causes of infection and persistence of the pathogen.

\section{ACKNOWLEDGEMENTS}

Claudio Verdugo is funded by FONDECYT 11130305.

\section{REFERENCES}

Castro-Ramos M, Tiscornia I, Loreno M, Sanguinetti C. 2014. Tuberculosis aviar en Rhea americana (Ñandú) en cautividad en Uruguay. Diagnóstico bacteriológico y molecular. Veterinaria 50, 45-64.

Converse KA. 2007. Avian Tuberculosis. In: Thomas NJ, Hunter DB, Atkinson CT (eds). Infectious diseases of wild birds. Blackwell Publishing, Iowa, USA, Pp 289-302.

Dhama K, Mahendran M, Tiwari R, Singh SD, Kumar D, et al. 2011. Tuberculosis in birds: insights into the Mycobacterium avium infections. Vet Med Int 2011. Article ID: 712369.

Gerhold RW, Fischer JR. 2005. Avian tuberculosis in a wild turkey. Avian Diseases 49, 164-166.

Godoy SN, Sakamoto SM, de Paula CD, Catão-Dias JL, Matushima ER. 2009. Detection of Mycobacterium avium in pet birds. Braz J Microbiol 40, 265-268.

Hejlicek K, Treml F. 1993. Epizootiology and pathogenesis of avian mycobacteriosis in the house sparrow (Passer domesticus) and tree sparrow (Passer montanus). Vet Med-Czech 38, 667-685.

Jorge MC, Traversa MJ, Schettino DM, Bernardelli A, Zumárraga M, et al. 2007. Tuberculosis en Rhea americana y Gallus sp. en cautiverio. In Vet 9, 35-42.

Kelly P, Jahns H, Power E, Bainbridge J, Kenny K, et al. 2013. Mycobacteriosis in ostriches (Struthio camelus) due to infection with Mycobacterium bovis and Mycobacterium avium complex. Avian Dis 57, 808-811.

Kul O, Tunca R, Haziroglu R, Diker KS, Karahan S. 2005. An outbreak of avian tuberculosis in peafowl (Pavo cristatus) and pheasants (Phasianus colchicus) in a zoological aviary in Turkey. Vet MedCzech 50, 446-450.

Muttalib AA, Riddell C. 1988. Epizootiology and pathology of avian tuberculosis in chickens in Saskatchewan. Can Vet J 29, 840-842.

Neira R, Rodríguez G, Silva A, Arias L, Inirida M, et al. 2006. Estudio macro y microscópico de la tuberculosis aviar en un zoológico de la sabana de Bogotá. Rev Med Vet 12, 7-21.

Sánchez FD, Yela IJ, Alfonseca E, Campuzano J, Morales E, et al. 2016. Respiratory tract infection caused by Mycobacterium bovis in a black swan (Cygnus atratus), Avian Pathol 45, 126-131.

Svastova P, Pavlik I, Bartos M. 2002. Rapid differentiation of Mycobacterium avium subsp. avium and Mycobacterium avium subsp. paratuberculosis by amplification of insertion element IS901. Vet Med 47, 117-121.

Tell LA, Woods L, Cromie RL. 2001. Mycobacteriosis in birds. Rev sci tech Off Int Epiz 20, 180-203.

Wilton S, Cousins D. 1992. Detection and identification of multiple mycobacterial pathogens by DNA amplification in a single tube. Genome Res 1, 269-273. 
